\title{
CLINICAL AND CYTOGENETIC STUDY OF TURNER SYNDROME
} AND ITS VARIANTS

\section{Shailaja CM ${ }^{1}$, Shobha ${ }^{* 2}$, Vijayakumar BJ ${ }^{3}$, Pravinkumar NK ${ }^{4}$.}

${ }^{1}$ Professor, Department of Anatomy, SSIMS \& RC, Davangere, Karnataka, India.

${ }^{* 2}$ Associate Professor, Department of Anatomy, JJMMC, Davangere, Karnataka, India.

${ }^{3}$ Professor \& Head, Department of Forensic Medicine \& Toxicology, SSIMS \& RC, Davangere, Karnataka, India.

${ }^{4}$ Associate Professor, Department of Forensic Medicine \& Toxicology, SSIMS \& RC, Davangere, Karnataka, India.

\section{ABSTRACT}

62 cases of Turner syndrome (T.S) were clinically diagnosed and sent to cytogenetic laboratory for confirmation of the diagnosis through karyotyping from 2012 to 2018. Out of 62 cases, 43 turned out to be T.S \& its variants. Most commonly observed karyotype was $45, X(62.79 \%)$, followed by $45, X / 46, X X(23.25 \%), 45, X / 46, X i(6.97 \%)$ mosaicism, $4.65 \%$ of $46, \mathrm{Xi} \& 2.32 \%$ of a very rare type of variant of T.S i,e $45, \mathrm{X} / 46, \mathrm{XY}$.

Patients with $45, X$ karyotype had typical features of T.S such as short stature ( $<5$ feet or $150 \mathrm{cms})$, delayed appearance of secondary sexual characters \& dysmorphic facies, the main complaint of these patients was primary amenorrhoea. Patients were younger at diagnosis \& had a significant shorter mean adult height than those with 45,X/46,XX mosaicism. Those with mosaicism had mild dysmorphic features \& presented with primary or secondary amenorrhoea. The rarest type of T.S $(45, X / 45, X Y)$ was presented in a new born with ambiguous genitalia (suspected for $\mathrm{CAH}$ ).

Short stature with sexual infantilism \& primary or secondary amenorrhoea in a young female should suggest the possibility of Turner syndrome, which should be confirmed by chromosome analysis.

KEY WORDS: Turner Syndrome and Variants, Cytogenetics.

Corresponding Author: Dr. Shobha, Associate Professor, Department of Anatomy, J. J. M. Medical College, Davangere, Karnataka, India. Mobile 9738403814, 9886740714

E-Mail: drshobhathanu@gmail.com

Access this Article online

Quick Response code

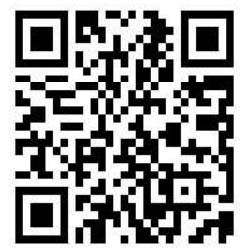

DOI: $10.16965 /$ ijar.2020.128

Journal Information

International Journal of Anatomy and Research

RG Journal ISSN (E) 2321-4287 | ISSN (P) 2321-8967

https://www.ijmhr.org/ijar.htm

DOI-Prefix: https://dx.doi.org/10.16965/ijar

Article Information

Received: 18 Feb 2020

Peer Review: 18 Feb 2020

Revised: None
Accepted: 02 Mar 2020

Published (O): 05 Apr 2020

Published (P): 05 Apr 2020

\section{INTRODUCTION}

Turner syndrome is the consequence of complete or partial absence of one $X$ chromosome in a phenotypic female usually characterized by short stature, gonadal dysgenesis \& a variety of other features.

In 1930, Otto Ullrich had reported on an 8 yrs old girl with short stature, lymphedema web neck, cubitus valgus \& dysmorphic features, which was the 1st case of T.S [1] But it was $1^{\text {st }}$ described as a distinct entity by Turner in 1938, in 7 females with short stature \& sexual infantilism, webbed neck \& cubitus valgus \& dysmorphic features [2].

Patients with 45,X/46,XY mosaicism exhibit a wide phenotypic spectrum ranging from normal male $(90 \%)$, which go unnoticed till puberty or 
present with hypospadiasis to male or female pseudo hermaphroditism. $10 \%$ females present with incomplete male development \& appear as partly masculinised female genitalia. The term Mixed Gonadal Dysgenesis (MGD)/ Disorder of Sex Development (DSD) is sometimes used for this group. Telvi et al in 1999 [3] reviewed post-natal ascertained $45, X / 46, X Y$ cases in which some males who appeared normal at birth can develop late onset "Turner syndrome like" abnormalities. New classification proposed by Chicago consensus (Hughes IA et al 2006 \& Lee et al 2006) [20] the term MGD has been employed in cases of testicular dysgenesis with $45, X / 46, X Y$ karyotype \& partial gonadal dysgenesis (PGD) in those with $46, X Y$ constitution, regardless of histological picture.

Patients with $\mathrm{Y}$ mosaicism have high risk for developing gonadoblastoma \& dysgerminoma. Here the main aim of our study is to co-relate the clinical profile with that of karyotypic abnormalities in a T.S \& its variants.

\section{MATERIALS AND METHODS}

62 cases of clinically diagnosed T.S were sent to the cytogenetic laboratory (SSIMS \& RC Davangere) for karyotyping from 2012 to 2018. All the cases were analysed \& evaluated prospectively.

Their presenting signs \& symptoms, clinical features \& the age of presentation were included. Hormonal profile (Serum FSH, LH \& Serum Electrolytes in special cases) \& pelvic ultrasound findings were also included in the study. A detailed evaluation of CVS was considered in suspected cases.

Peripheral blood lymphocyte culture was carried out by standard technique of Moorhead et al $[3,5]$. Trypsin \& Giemsa or G banding of metaphase chromosomes was carried out. 25 metaphases of each patient were analysed, if any one metaphase showed a different arrangement of chromosomes then another 25 metaphases were analysed. If the different cell line was noted again then another 25 metaphases were analysed with a total of 75 metaphases. This was done to rule out mosaicism. Serum FSH, LH were analysed in standard laboratory with ELISA method. In one of our case with ambiguous genitalia (suspected for congenital adrenal hyperplasia), serum electrolytes were also analysed.

The mean age ( $>16$ years) \& mean adult height ( $<5$ feet $/ 150 \mathrm{cms}$ ) at the time of diagnosis were compared with $45, X \& 45, X / 46, X X$ mosaic group. These features were not compared with third group which showed heterogonous mix of chromosomal abnormalities associated with T.S.

\section{RESULTS}

Table 1: Cytogenetic abnormalities observed in T.S are shown below.

\begin{tabular}{|l|c|}
\hline \multicolumn{1}{|c|}{ Normal } & Number \\
\hline $46, \mathrm{XX}$ & 19 \\
\hline CLASSIC & \\
\hline $45, \mathrm{X}$ & 27 \\
\hline MOSAICISM & \\
\hline $45, \mathrm{X} / 46, \mathrm{XX}$ & 10 \\
\hline OTHER/ THIRD GROUP & \\
\hline $45, \mathrm{X} / 46 \mathrm{Xi}(\mathrm{Xq})$ & 3 \\
\hline $46, \mathrm{Xi}(\mathrm{Xq})$ & 2 \\
\hline $45, \mathrm{X} / 46, \mathrm{XY}$ & 1 \\
\hline TOTAL & $\mathbf{6 2}$ \\
\hline
\end{tabular}

Monosomy X (45,X): Out of 27 cases with $45, X$ karyotype ,18 patients were $d^{\prime \prime} 16 y r s$, including a new-born (2days old). Other 9 patients were above the age of 16.The mean age at the timeof diagnosis was $15 y$ rs. The mean adult height was $123.6 \mathrm{cms}$ (Table 2). The presenting complaint of 18 patients was short stature with some physical findings as shown in Table 2.The new born presented with ambiguous genitalia. Other 9 patients presented with primary amenorrhoea as their main complaint.

45,X/ 46,XX Mosaicism: Out of 10 patients in this group , 7 were of $>16$ yrs of age while other 3 were $d^{\prime \prime}$ than $16 y$ rs of age. The mean age at diagnosis was 19 yrs \& the mean adult height was $152.2 \mathrm{cms}$.

In 7 patients main presenting complaint was primary amenorrhoea, in other 3 patients - one presented with secondary amenorrhoea, other 2 presented with short stature \& delayed sex characters. All other Turner stigmata were infrequently seen (Table 2).

Other $X$ chromosome abnormalities associated with Turner syndrome: Apart from 45,X $\& 45, X / 46 X X$ mosaicism other cytogenetic abnormalities seen are shown in Table 1. 
Out of 6 patients, 3 patients showed $45, X / 45 X i$ (Xq), 2 patients showed 46,Xi (Xq) \& 1 patient (new born) showed 45,X/46,XY.

5 patients of this group were $>16$ yrs of age. Mean age at diagnosis was 19 yrs of age $\&$ mean adult age was $156 \mathrm{cms}$. Out of 5 patients 3 presented with primary amenorrhoea with delayed sex characters \& 2 patients with secondary amenorrhoea.Other physical features are as shown in Table 2.

The new born with mosaicism for $Y$ chromosome suspected for $\mathrm{CAH}$ was included in our study as it had presented with ambiguous genitalia (external genitalia showed a large phallus of $1.3 \mathrm{cms}$, with no separate urethral opening, urogenital sinus with wide opening, scrotal sac with rugocity seen, but no contents, no hernia in inguino-perineal region seen) \& had a characteristic Turner phenotype.

Hormonal profile: Estimation of serum FSH \& LH could be elicited in only 21 patients out of 34 who were above the age of $15 \mathrm{yrs}$. This includes 9 patients in 45,X Monosomy, 7 patients in $45, X / 46 X X$ mosaicism \& 5 patients in other group of karyotype. The mean FSH \& LH levels were $55.6 \pm m 45.4$ (range-1.8-172) \& $18.3 \pm 15.1$ (range0.8-51.5) $\mathrm{mlU} / \mathrm{ml}$, respectively. These levels were not compared between these three groups, as the number of patients in each type was very small.

As the new born was suspected for Congenital Adrenal Hyperplasia (CAH), serum electrolytes were analysed (serum sodium $130.5 \mathrm{mmol} / \mathrm{l}$, serum potassium $5.5 \mathrm{mmol} / \mathrm{l} \&$ serum chloride $100.1 \mathrm{mmol} / \mathrm{l})$, all were within normal limits, \& were estimated for 3 consecutive days.

Thyroid function tests were carried out in 12 patients, who came with main complaint as short stature. Out of 12 patients, 3 of them showed elevated TSH \& low thyroxin levels suggesting early hypothyroidism. They were referred to endocrinologist for further evaluation.

Pelvic ultrasound: Pelvic ultrasound findings were available for 20 out of 34 patients who were more than $15 \mathrm{yrs}$ of age. These comprised of 9 patients with $45, X, 6$ patients with $45, X / 46, X X \&$ 5 patients from other group of karyotype.

$50 \%$ of these patients showed hypoplastic uterus with bilateral streak ovaries. $35 \%$ of them showed unilateral or bilateral absence of ovaries \& $15 \%$ of them showed normal uterus \& ovaries. While the new born with ambiguous genitalia showed presence of uterus $(2.7 \mathrm{cms} x$ $9 \mathrm{~mm} \times 1.5 \mathrm{cms}$ ) with normal endometrium. No suggestions of testis like structure seen in inguino-perineal region. Kidneys \& adrenal glands were normal in size \& echo-texture.

Table 2: Clinical co-relation with karyotype in T.S \& its variants are shown in table 2 . (percentage).

\begin{tabular}{|l|c|c|c|}
\hline \multicolumn{1}{|c|}{ Features } & $\begin{array}{c}45 \mathrm{X} \\
\mathrm{N}-27\end{array}$ & $\begin{array}{c}45, \mathrm{X} / 46, \mathrm{XX} \\
\mathrm{N}-10\end{array}$ & $\begin{array}{c}\text { Others } \\
\mathrm{N}-6\end{array}$ \\
\hline Short stature & 90 & 75 & 78 \\
\hline Dysmorphic face & 50 & 10 & 10 \\
\hline Short neck & 10 & 5 & 5 \\
\hline Low posterior hair line & 5 & 0 & 0 \\
\hline Cubitus valgus & 25 & 0 & 0 \\
\hline Shield chest & 35 & 5 & 4 \\
\hline Delayed sex characters & 100 & 75 & 56 \\
\hline Primary amenorrhoea & 100 & 65 & 80 \\
\hline Secondary amenorrhoea & 0 & 35 & 20 \\
\hline Congenital heart disease & 5 & 0 & 0 \\
\hline I.Q/ mental ability & 5 & 0 & 0 \\
\hline Mean age at diagnosis (years) & 15 & 19 & 19 \\
\hline Mean adult height (cms) at diagnosis & 123.6 & 152 & 156 \\
\hline
\end{tabular}

\section{DISCUSSION}

The approximate incidence of Turner syndrome is estimated to be 1 in 2500 live female births [8]. $45, X$ cell line occurs as a result of non- disjunction at either stage of meiosis 1 or 2 during spermatogenesis or oogenesis or from post zygotic error.

It is suggested that a gene dosage inequality due to absence of part or all of the X chromosome is responsible for the phenotype [9-11].

Prior to 12 weeks of in-utero development, the ovaries in 45 , $X$ female appear normal histologically, but thereafter, there is a decrease in the number of follicle cells per oocyte. In the absence of second $X$ chromosome, the oocytes degenerate more rapidly than normal, so that at the time of birth there are few, if any left, the ovarian tissue resembles fibrotic streaks [11]. The streak gonads appear identical regardless of karyotype [6].

Short stature \& primary amenorrhoea were the commonest presenting complaints of our patients, regardless of karyotype. The final adult height was significantly less in patients with 
45,X, karyotype when compared with 45,X/46XX mosaicism $(p<0.05)$. Other common features like dysmorphic facies, cubitus valgus, shield chest (table2) are seen in $45, X$ group $\&$ infrequently in $45, X / 46 X X$ \& less frequently in third group.

Few of the patients with $45, X / 46 X X$ mosaicism had secondary amenorrhoea (Table -2 ). These patients had low levels of mosaicism i,e more of $46, X X$ than $45 X$. Between $10-20 \%$ of the patients with T.S have spontaneous onset of menstruation [11]. This is seen less often in 45X group. Pregnancy was reported in 2 of our patients, one with $45, X / 46, X X \&$ other patient with Isochromosome 46,Xi(Xq). Pregnancy is rare in patients with $45, X$ group. Approximately more than half of the patients of T.S are likely to have miscarriages, foetal malformations or chromosomal abnormalities [7].

Mental ability was normal in our patients, only 2 patients with $45, X$ had IQ less than $60 \%$. A much higher incidence of mental disability has been reported in patients with a ring chromosome [12].

Only 2 of our patients had congenital cardiovascular anomaly. Both females belonged to $45, X$ group \& had atrial stenosis. The incidence of congenital heart disease in Turner syndrome is reported to be highest in $45, X$ group $(10-15 \%)$ \& lowest in other group (0-8\%) comprising long or short arm deletions of $X$ chromosome $[11,10,4,6]$.

2-5\% of Turner syndrome patients show mosaicism for $Y$ chromosome. We had a new born with $45, X / 46, X Y$ karyotype $\&$ had a characteristic Turner phenotype. Traditionally these patients are said have mixed gonadal dysgenesis.

Dysgenetic testis may be bilateral or associated with contra lateral streak in subjects with $45, \mathrm{X} /$ 46XX karyotype. Histologically, they may show fibrous tissue \& few tubular structures with reduced germ cells. As a consequence, the external genitalia ranges from male to female, including cases of striking genital ambiguity \& persistence of mullerian structure [19].

Patients with $\mathrm{Y}$ chromosome are at high risk for developing gonadoblastoma [14]. Recently, molecular methods have been used to demonstrate the SRY gene in these patients, as a marker for $Y$ chromosome [15].
Serum gonadotropin levels were high in most of our cases with FSH levels being consistently higher than LH levels. Although the release of both hormones is stimulated by gonadotropin releasing hormone, but the metabolic clearance of both hormones is different \& becomes responsible for FSH exceeding than that of $\mathrm{LH}$ levels [10]. However some of our patients showed normal levels of FSH \& LH.

Bio-chemical findings in 3 of our patients showed high levels of TSH \& low levels of thyroxin suggestive of early hypothyroidism. A high incidence of autoimmune hypothyroidism is reported in T.S, thus highlighting, the importance of thyroid function evaluation in these patients [9].

Pelvic ultrasound findings in $50 \%$ of our patients showed hypoplastic uterus with bilateral steak ovaries. $35 \%$ of them showed unilateral or bilateral absence of ovaries \& $15 \%$ of them showed normal uterus \& ovaries. New born with $45, X / 46, X Y$ karyotype presented with ambiguous genitalia (external genitalia showed a large phallus, with no separate urethral opening, scrotal sac seen but no contents, no hernia in inguino-perineal region seen). As mosaic for $Y$ chromosome are at high risk for developing gonadoblastoma, follow up of the patient till puberty was suggested.

Recent recommendations are in favour of using recombinant growth hormone in Turner syndrome [16]. Growth hormone increases growth velocity \& leads to an average gain of $5 \mathrm{cms}$ in terms of final height [17]. But none of our adult patients received recombinant growth hormone.

\section{CONCLUSION}

Turner syndrome is a chromosomal disorder which is frequently misdiagnosed or missed completely. The severity of the syndrome decreases as it becomes mosaic. Hence any female of short stature with primary or secondary amenorrhoea, even with the absence of other phenotypic features of T.S should be suspected as T.S but confirmed by chromosomal analysis (karyotyping).

Abnormal maternal serum levels \& anomalies of kidney \& uterus during $2^{\text {nd }}$ trimester should 
warn for karyotyping. Early recognition of T.S \& timely investigations will help in improving the quality of life, by improving the adult height in those responding to growth hormone therapy \& initiating sex hormone replacement. Genitoplasty \& gonadectomy should be preferred in those with y chromosomal material, as they are at risk for developing gonadoblastoma or dysgerminoma later in life. Such patients are asked for follow up, to monitor their growth \& puberty.

\section{Conflicts of Interests: None}

\section{REFERENCES}

[1]. Turner HH. A syndrome of infantilism, congenital webbed neck \& cubitus valgus. Endocrinology.1938; 23:566-78.

[2]. Ullrich O. Turner syndrome \& status Bonnevie Ullrich. Am J Hum genet 1949; 1:179-85.

[3]. Moorhead PS, Nowell PC, Mellaman WJ, Battips DM and Hungerford DA. Chromosome preparation of leukocyte cultures from human peripheral blood. Exp cell Res 1960; 20:613-16.

[4]. Lemli L and Smith DW. The XO syndrome: a study of different phenotype in 25 patients. J Pediatr 1963; 63:577-88.

[5]. Sea bright M. A rapid banding technique for chromosomes. Lancet 1971;

2: 971-72.

[6]. Simpson JL. Gonadal dysgenesis \& sex abnormalities of human sex chromosomes: current status of phenotypic-karyotypic correlation. BDOAS 1975;11:23-59.

[7]. King CR, Magenis E and Bennet S. Pregnancy \& Turner syndrome. Obstet Gynecol 1978; 52:617-24.

[8]. Hook EB and Warburton D. The distribution of chromosome genotypes associated with Turner syndrome: live birth prevalence rated \& evidence for diminished foetal mortality \& severity in genotype associated with structural $X$ abnormalities or mosaicism. Hum genet 1983; 64:24-7.
[9]. Pependieck LG, Lorcansky S, Coca R, et al. High incidence of thyroid disturbances in 49 children with Turner syndrome. J Pediatr 1987; 111: 258-61.

[10]. Lippe BM, Primary ovarian failure. In Clinical Pediatric Endocrinology. Ed Kaplan SA. Philadelphia, W.B. Saunders Company. 1990; 325-66.

[11]. Hall JG and Gilchrist DM, Turner syndrome \& its variants. Pediatr clin North Am. 1990; 37:1421-40.

[12]. Van Dyke DL, Wiktor A, Roberson JR and Wiess L. Mental retardation in Turner syndrome. J Pediatr. 1991; 118: 415-17.

[13]. Dawson Falk KL, Wright AM, Bakker B, Pitlick PT, Rosenfeild RG cardiovascular evaluation in Turner syndrome : utility of MR imaging . Australias Radiol 1992; 36: 1376-1380.

[14]. Krasna IH,Lee ML, Smilow P, Sciorra L and Eierman L. Risk of malignancy in bilateral streak gonads. The role of $Y$ chromosome. J Pediatr Surg 1992; 27:1376- 80 .

[15]. Medlej R, Lobaccaro JM, Berta P, et al. Screening for $Y$ - derived sex determining gene SRY in 40 patients with Turner syndrome. J. Clin Endocrinol Metab. 1992; 75: 1289-92.

[16]. Ranke MB. Current concepts in the treatment of Turner syndrome with special reference to the treatment of short stature. Acta Pediatr Jpn. 1992; 34:183-94.

[17]. Rongen Westerlaken C and Wit JM. Turner syndrome: A virtually certain indication for growth hormone treatment. Tijdschr Kindergeneeskd. 1992; 60: 15563.

[18]. Telvi I, Libber A, Del Pino O, Barbet, JP and Chaussain JL. 45,X/46XY mosaicism: Reported 27 cases. Paediatrics 1999;104:304-8.

[19]. Scolfaro MR, Caidinalli IA and Guerra junior G.A. Importtanica da analise histological morfometrica Gonadal na identificacao da gonada disgenetica Arq Bras End Metab 2003; 47: 128-34.

[20]. Hughes IA, Houk C, Ahmed SF, Lee PA, Jwpes1/ESPE2 Consensus group. Consensus statement on management of intersex disorders. Arch Dis Child 2006; 91:554-62.
How to cite this article: Shailaja CM, Shobha, Vijayakumar BJ,
Pravinkumar NK. CLINICAL AND CYTOGENETIC STUDY OF TURNER
SYNDROME AND ITS VARIANTS. Int J Anat Res 2020;8(2.1):7440-
7444. DOI: $10.16965 /$ ijar.2020.128 